\title{
On the Development of a Reference Framework for ICT for Manufacturing Skills
}

\author{
Ahmed Bufardi and Dimitris Kiritsis \\ Ecole polytechnique Fédérale de Lausanne (EPFL), Switzerland \\ \{ahmed.bufardi,dimitris.kiritsis\} @epfl.ch
}

\begin{abstract}
In this paper, we plead for the development of a reference framework for ICT for manufacturing skills. The existing e-skills frameworks are either too general or too restrictive. That is why there is a need for a reference framework for ICT skills in manufacturing to be used as a common reference by all Industrial Learning stakeholders when dealing with issues related to ICT skills in manufacturing. The framework should be capable to capture most of state-ofthe-art e-skills relevant to manufacturing in addition to the skills related to emerging ICT for manufacturing. Such a framework would encourage manufacturing workers to take training on specific ICT skills. The motivation for pleading for a reference framework for ICT for manufacturing skills and the requirements related to its development are presented in this paper.
\end{abstract}

Keywords: Industrial Learning, e-skills, ICT for Manufacturing, reference framework.

\section{Introduction}

The work presented in this paper was developed in ActionPlanT project. It relates to the review of existing e-skills frameworks, the identification of the gaps in these frameworks and the definition of the requirements to address these gaps mainly through a reference framework for Information and Communication Technologies (ICT) for manufacturing.

ActionPlanT is co-funded by the European Commission under the Private-Public Partnership (PPP) "Factories of the Future" initiative of the Seventh Framework Programme (FP7) for research and technological development (Grant Agreement Number 258617). The project started in June 2010 and ended in May 2012. The two main activities of ActionPlanT are:

- Establishing an ICT-enabled manufacturing vision for use cases and services of the future using this analysis as a basis. This vision paves the way for a detailed roadmap which prioritizes and schedules most promising topics for the upcoming Horizon 2020 Programme;

- Developing and validating a concept for Industrial Learning (IL), extensively piloted via Industrial Learning Pilot Events (ILPEs) and workshops amongst stakeholders in industry, academia, and the European technology platforms. 
The work described in this paper relates to the second activity "Awareness \& industrial Learning".

In ActionPlanT, IL is defined as the process of identifying and implementing professional competences triggered by new scientific and technological knowledge and implemented in an industrial context to address new professional needs (i.e., what workers have to cover and to know in order to contribute to new objectives such as business conversion, enlargement, modernization, etc.).

In ActionPlanT context, we have to do with the development and implementation of new competencies required by new professional needs created by recent achievements of research and innovation actions in the domain of ICT for manufacturing.

The reference framework discussed in this paper is intended to establish the skills related to ICT for manufacturing and IL as defined in ActionPlanT is the means through which the manufacturing workforce can acquire these skills in order cover new professional needs.

The paper is organized as follows. Section 2 is devoted to motivating our plea for the development of a reference framework for ICT for manufacturing. The definition of e-skills is provided in Section 3. Section 4 is presenting the requirements of ICT for manufacturing skills framework. Discussions related to this framework are given in Section 5. Finally, Section 6 presents concluding remarks about the framework.

\section{Motivation for a Reference Framework for ICT for Manufacturing Skills}

The investment and efficient usage of ICT plays a major role in boosting productivity. Between 1995 and 2004, the US enjoyed a higher average productivity growth than most of the EU member states and the average of all EU15 member states [1]. This is linked to the superior capacity of US businesses to adapt and make the best possible use of emerging technologies, the most prominent being ICT.

IL will face major challenges as new skills will be required by the future workforce [2-4] to deal with new professional needs. On the basis of these needs, approaches to IL and training that introduce emerging concepts appear in the literature [5]. Manufacturing industry is one of the domains where the need for new skills mainly those related to ICT is crucial for competitiveness and innovation.

Policy has also taken notice and action to address this; the EC issued a communication [6] on e-skills for the 21st century establishing a long term agenda for e-skills, and defining 5 action lines at the EU level: promoting long-term cooperation and monitoring progress, developing supporting actions and tools, raising awareness, fostering employability and social inclusion, and promoting better and greater use of e-learning.

The main e-skills frameworks, developed by different professional and institutional sources, have been reviewed in terms of their relevance with current and future ICT in manufacturing. The outcomes from the review of the e-skills frameworks and related issues are summarized in Table 1. 
Table 1. Review of existing e-skills frameworks

Observation
The use of different terms such as e-skills, digital skills, ICT
skills, etc. is confusing and negatively impacting the review
and search for e-skills
The reviewed e-skills frameworks are either too general or too
restrictive

The e-skills from different frameworks are given in various formats and different levels of detail which raises coherence problems when putting them together

Many of the skills in the reviewed frameworks considered as
e-skills are not explicitly exhibiting ICT (neither software nor
hardware) features to qualify them as e-skills

There are manufacturing working areas which are not covered by the skills from reviewed frameworks (e.g., e-skills to use supply chain management system, how to set-up manufacturing systems, factory planning, layout planning)

The e-skills in the reviewed frameworks concern classical manufacturing systems. Issues such as agile manufacturing and collaborative networks are not covered or only to a very limited extent

The reviewed frameworks are not capable to capture the new e-skills relating to the ICT for manufacturing issues such as IoT, web-services, digital factory, cloud manufacturing, etc.

\section{Comment}

The use of a common terminology and a clarification of the difference between these terms are required

A framework devoted to e-skills in manufacturing is needed

A standard way of representing and writing e-skills can be useful

It may be useful to rewrite them in a way to emphasize the ICT features they involve if there are any

It may be useful to investigate whether these working areas are not requiring $e$-skills or they require e-skills which are not yet defined and used

There is a need for defining new eskills corresponding to advanced ICT for manufacturing

A new framework is needed for the definition of these new e-skills

The major outcome from the observations in Table 1 is the lack of a set of e-skills capable to cover professional needs related to advanced ICT for manufacturing which are needed by manufacturing companies to improve their competitiveness.

Automotive industry is the industrial sector the most investigated with respect to the development of ICT for manufacturing skills. The ICT skills are defined in relation to the different working areas of automotive production [7]. Being specific to automotive industry, this framework is too restrictive to be used a general framework for ICT for manufacturing.

The e-CF (e-Competence Framework) [8] suggests definitions to the key learning concepts of competence, knowledge, skill, and attitude, which have been developed within a European ICT business environment. It comprises 36 ICT competences that can be used and understood by ICT users and supply companies, the public sector, educational and social partners across Europe. The proposed list of competencies is assumed to be common to all industrial sectors and is not specific for manufacturing.

The digital skills presented in [9] are developed for users of digital technology in the Canadian workplace. The corresponding framework is too general to be used as a reference framework for ICT for manufacturing skills.

The existing e-skills frameworks are either too general or too restrictive to be used as a reference framework for ICT for manufacturing skills. That is why there is a need for developing a framework focusing on manufacturing which is capable to capture 
most of state-of-the-art e-skills relevant to manufacturing in addition to new skills related to emerging ICT for manufacturing.

A manufacturing-focused e-skills framework could well differ from the existing eskills frameworks either promoted by ICT vendors or developed for specific sectors or general purposes. That is why we propose to base the manufacturing-focused eskills framework on the decomposition of the manufacturing system into subsystems and sub-subsystems. The e-skills are defined at the level of sub-subsystems.

\section{Defining e-Skills}

This paper focuses on e-skills for manufacturing. The European e-Skills Forum adopted in 2004 a definition of the term "e-skills" covering 3 main categories [10]:

- ICT practitioner skills: the capabilities required for researching, developing, designing, strategic planning, managing, producing, consulting, marketing, selling, integrating, installing, administering, maintaining, supporting and servicing ICT systems.

- $\quad$-business skills: the capabilities needed to exploit opportunities provided by ICT; to ensure more efficient and effective performance of different types of organizations; to explore possibilities for new ways of conducting business/ administrative and organizational processes; and/ or to establish new businesses.

- ICT user skills: the capabilities required for the effective application of ICT systems and devices by the individual. ICT users apply systems as tools in support of their work. User skills cover the use of common software tools and of specialized and more advanced tools. At the general level, they cover "digital literacy".

There is a large consensus among stakeholders that e-skills are crucial to boost competitiveness, productivity and innovation as well as the professionalism and employability of the workforce in industry [11].

The majority of European workforce has a good level of basic ICT skills (e.g., email communication and use of basic office applications) as a result of the investments made in this domain [12]. However regarding advanced ICT skills, there is a gap between the actual capabilities of the European workers and the expectations of and requirements for ICT skills of their employers [12].

\section{Requirements for the ICT for Manufacturing Skills Framework}

\subsection{Decomposing the Manufacturing System}

For the development of a manufacturing e-skills framework, we consider the decomposition of the manufacturing system into 5 subsystems [13]: inputs, manufacturing process, outputs, management and control, and support.

The 5 subsystems and their related links are represented in Figure 1. 
We selected this decomposition for the following reasons:

- The subsystems are common to all manufacturing systems.

- All important criteria governing the manufacturing system behaviour are reflected in these subsystems.

- This model is suitable for modelling any manufacturing system structure.

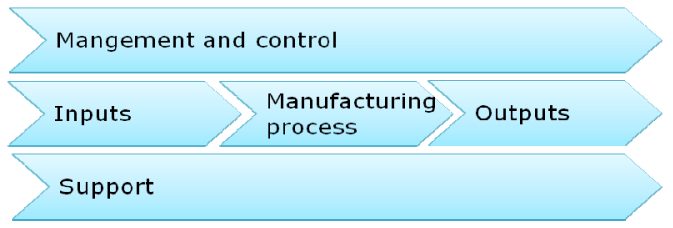

Fig. 1. Subsystems of the manufacturing system

The 5 subsystems of the manufacturing system are too broad to allow the identification of specific corresponding e-skills. That is why these subsystems are decomposed further into sub-subsystems which are more detailed and the manufacturing e-skills are associated to the sub-subsystems of the manufacturing process.

The use of this decomposition allows capturing most of the state-of-the-art e-skills relevant to manufacturing (see examples in Table 2).

Table 2. Examples of state-of-the-art e-skills for management and control subsystem

\begin{tabular}{lll}
\hline $\begin{array}{l}\text { Manufacturing sub- } \\
\text { subsystem }\end{array}$ & ICT skill & Reference \\
\hline $\begin{array}{l}\text { Strategy } \\
\text { formulation }\end{array}$ & $\begin{array}{l}\text { Contributing to the development of ICT strategy and } \\
\text { policy } \\
\text { Analyzing future developments in business process and } \\
\text { technology application }\end{array}$ & European e-CF \\
& $\begin{array}{l}\text { Analyzing costs and benefits of implementing new ICT } \\
\text { solutions }\end{array}$ & European e-CF \\
$\begin{array}{l}\text { Performance } \\
\text { appraisal and } \\
\text { monitoring }\end{array}$ & $\begin{array}{l}\text { Selecting appropriate ICT solutions based upon benefit, } \\
\text { risks and overall impact }\end{array}$ & European e-CF \\
$\begin{array}{l}\text { Production planning } \\
\text { and control }\end{array}$ & $\begin{array}{l}\text { Optimizing of production control by the use of } \\
\text { PPS-systems/software }\end{array}$ & $\begin{array}{l}\text { Automotive ICT } \\
\text { skills }\end{array}$ \\
\hline
\end{tabular}

\subsection{Role of ActionPlanT}

The ActionPlanT IL model [14] is suitable for creating new knowledge assets related to "cutting edge" ICT for manufacturing, identifying corresponding new professional competencies, and defining relevant learning programs and actions to train workers and engineers to develop these competencies. 
The other important result of ActionPlanT project is the roadmap. It is built around 5 clusters aligned with the 5 innovative aspects established in the ActionPlanT vision. These clusters are: (i) Towards Agile Manufacturing Systems \& Processes, (ii) the new Seamless Factory Lifecycle Management, (iii) People at the Forefront, (iv) Fostering Collaboration Supply Network, and (v) Aiming at Customer Centric Design and Manufacturing.

Each research priority within the clusters is evaluated with respect to the 5 ambitions: On-demand, Optimal, Innovative, Green, and Human-Centric.

The ActionPlanT roadmap and vision provide a relevant framework for defining new e-skills related to emerging and advanced ICT for manufacturing. They also provide a basis for defining the broad topic areas for which content should be developed in the framework of the training programs required for the transfer of the new e-skills to the manufacturing workforce to cover new professional needs.

\subsection{Other Requirements}

ICT skill (e-skill) for manufacturing is the basic concept in the framework. That is why there is a need for a clear definition of such concept. It is important to know when a skill can be qualified as ICT skill/e-skill.

The decomposition of the manufacturing process should also be flexible to allow for the addition of new sub-subsystems that may result from new developments in manufacturing technologies.

As ICT is changing very fast, the ICT skills needed for manufacturing are also evolving very fast. That is why the framework should be updateable to allow for the addition of new e-skills that result from new developments in ICT for manufacturing.

There is a need for continuous follow up of the evolution of ICT for manufacturing to make the involved actors aware of the emerging ICT for manufacturing skills they may need for their businesses.

To be appropriate for small and medium enterprises (SME), the framework should not be too specific. Since SME are the companies that most need IL to develop ICT for manufacturing skills that can help them extend, improve their businesses or develop new ones, then it is important to take this issue into account.

\section{Discussion}

The ICT for manufacturing framework we are pleading for its development is intended to be used as a common reference framework by all IL stakeholders when dealing with issues related to ICT for manufacturing skills. That is why; the development of such a framework should be dealt with in a collaborative way between all IL stake-holders to arrive at a consensus solution acceptable by all involved actors.

The effective development of the framework can be done by a specialized European working group composed of representatives of the different IL stakeholders as it was the case for the development of the European e-CF. 
Since ICT are characterized by a very fast evolution, then an important issue to be faced by the framework for ICT for manufacturing is the update of the list of related skills to keep up with the pace of technological change.

Most companies are not aware of the emerging e-skills for manufacturing triggered by the new trends and innovations in ICT for manufacturing that can help them extend their businesses or develop new ones. They need to be regularly informed about the emerging e-skills for manufacturing.

An observatory for a continuous follow-up of the main trends and innovations in ICT for manufacturing, identifying the related ICT for manufacturing skills, and communicating the information to the different IL stakeholders can be a useful solution to the problem. Such an observatory can benefit from the experience and the way of working of other observatories in other domains which have similar objectives.

The competencies/skills from literature are provided in different formats and levels of detail. A common reference framework for ICT for manufacturing skills can provide a basis for developing a coherent and uniform list of ICT for manufacturing.

\section{Conclusion}

The extensive review of e-skills literature revealed the absence of a reference framework for e-skills in manufacturing which can be used as a common reference by all IL stakeholders and which is capable of capturing the main ICT skills which are needed by manufacturing companies to promote innovation and excellence.

Most of the e-skills from existing frameworks are basic e-skills and are not suitable for the implementation and application of advanced ICT for manufacturing. This motivated our plea for the development of a reference framework for ICT for manufacturing skills capable not only to capture most of state-of-the-art e-skills related to manufacturing but also the skills induced by emerging ICT for manufacturing.

Since ICT are changing very fast, the reference framework should be updateable to allow for the integration of new e-skills that may result from new developments in ICT for manufacturing.

As the framework is intended to be used as common reference by all IL stakeholders, then its development should be realized in a collaborative way taking into account the requirements and views of all concerned parties.

We believe that such a framework will support:

- Companies to determine which training is needed to acquire specific ICT for manufacturing skills.

- Training providers to adopt curricula from "cutting-edge" ICT and tailored delivery mechanisms.

- Fast transfer of ICT for manufacturing from research to industry.

- Etc.

Acknowledgements. The research leading to these results has received funding from the European Community's Seventh Framework Programme (FP7/2007-2013) under grant agree-ment $n^{\circ} 258617$. 
The work in the ActionPlanT project is a common effort among all its contributing partners: Agoria, EPFL, Fraunhofer IPK, Dassault Systèmes, POLIMI, SAP, Tecnalia, University of Patras, and Platte Consult.

We would like also to thank the experts that participated in the validation workshop which took place in Athens in May 2012 for their valuable contribution to the validation or suggestion of recommendations related to ICT for manufacturing skills.

\section{References}

1. Van Ark, B., Inklaar, R.C.: Catching Up or Getting Stuck? Europe's Troubles to Exploit ICT's Productivity Potential', Research Memorandum GD-79, Groningen Growth and Development Centre (September 2005), http://www.e-library.1t/resursai/ ES/memorandumai/gd79.pdf

2. FuTMaN, Future of manufacturing in Europe 2015-2020 - the challenge for sustaina-ble development, Final Report (2003)

3. MATAP WG Education, Manufacturing Education Challenges \& Actions, Working Document (2003)

4. Chryssolouris, G., Mavrikios, D., Papakostas, D.N., Mourtzis, D.: Education in Manufacturing Technology \& Science: A view on Future Challenges \& Goals. Inaugural Keynote. In: Proceedings of the International Conference on Manufacturing Science and Technology (ICOMAST 2006), Melaka, Malaysia (August 2006)

5. Mavrikios, D., Papakostas, N., Mourtzis, D., Chryssolouris, G.: On industrial learn-ing \& training for the Factories of the Future: A conceptual, cognitive \& technology frame-work. Journal of Intelligent Manufacturing, Special Issue on Engineering Education (2011), doi:10.1007/s10845-011-0590-9

6. European Commission, E-Skills for the 21st century: Fostering competitiveness, growth and jobs. Communication from the commission to the council, the European parlia-ment, the European economic and social committee and the committee of the regions. Brussels: $\operatorname{COM}(2007) 496$ final (2007), http://ec.europa.eu/enterprise/sectors/ ict/files/comm_pdf_com_2007_0496_f_en_acte_en.pdf

7. Spöttl, G., Becker, M.: ICT practitioner skills and training: automotive industry, Cedefop Panorama series; 91, Luxembourg: Office for Official Publications of the European Communities (2004), http: / / www. edis.sk/ekes / TIAF0 4004 ENC_0 02 .pdf

8. European e-Competence Framework 2.0 - User Guide CWA Part II, http: //www. ecompetences.eu/site/objects/download/ 5999_EUeCF2.0userguide.pdf

9. Chinien, C., Boutin, F.: Defining essential digital skills in the Canadian workplace: final report, Montreal, Quebec: WDM Consultants (2011),

http: / / www.nald.ca/library/research/digi_es_can_workplace/ digi_es_can_workplace.pdf

10. European E-Skills 2009 Conference: Fostering ICT Professionalism, Brussels, Conference Report (November 2009), http: / / ec . europa. eu / enterprise/sectors / ict/ files/european_eskills_2009conference_report_en.pdf

11. McCormack, The E-Skills Manifesto: A Call to Arms, European School net, Brussels, Belgium (2010) 
12. Kolding, M., Kroa, V.: e-Skills - The key to Employment and Inclusion in Europe, IDC White Paper, Sponsored by Microsoft (January 2007)

13. Singh, V., Agrawal, V.P.: Structural modeling and analysis of manufacturing systems using graph theoretic approach. Journal of Manufacturing Technology Management 19, 844-870 (2008)

14. Kiritsis, D., Bufardi, A., Mavrikios, D., Knothe, T., Szigeti, H., Majumdar, A.: A Competence-Based Industrial Earning Approach for Factories of the Future: A Result of the FP7Fof Project ActionPlanT. In: 4th International Conference on Computer Supported Education, CSEDU 2012, Porto, Portugal, April 16-18 (2012) 